\title{
Alarm in US over database antipiracy bill
}

[WASHINGTON] Legislation aimed at strengthening the intellectual property protection of commercial databases is moving quickly through the US Congress, alarming many science advocates who say it will have a chilling effect on the free flow of information among academic researchers.

The Collections of Information Antipiracy Act (HR 2652), sponsored by Howard Coble (Republican, North Carolina), passed the House of Representatives with little debate in May. A Senate counterpart, S 2291, was introduced by Rod Grams (Republican, Minnesota) this month, and is scheduled for hearings in the autumn.

The proposed legislation would prohibit the extraction or commercial use of "all or a substantial part... of a collection of information gathered, organized, or maintained by another person through the investment of substantial monetary or other resources".

The bill is designed to protect large commercial databases from electronic piracy. It is backed by a powerful group of publishers, including Reed Elsevier (publisher of the Lexis Nexis database and Elsevier science journals) and Thomson Corporation, parent company of the West Group, which owns the Westlaw online legal research service and is based in Grams' home state of Minnesota.

But the bill is opposed by science and library associations, including the American Association for the Advancement of Science (AAAS) and the Association of American Universities (AAU).

They warn that the protection offered to commercial database owners is too sweeping, and could have serious unintended consequences for the research community. Scientists could end up paying for access to their own data after they have been repackaged

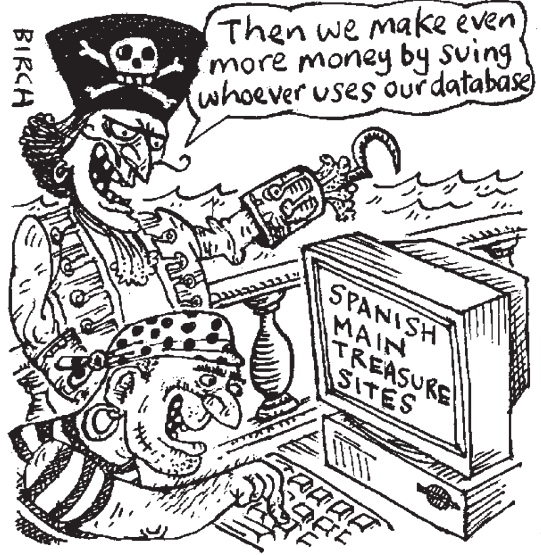

by a commercial database owner.

Researchers who adapt, modify and share data from a wide variety of sources could become paralysed by the fear of lawsuits. "The potential for litigation is phenomenal," says Debra Stewart, vice-provost at the North Carolina State University, who testified against the bill on behalf of the AAU earlier this year.

The legislation would be "a mess, a disaster", warns Mark Frankel of the AAAS, adding that it could lead to a fundamental shift in the culture of science. Entrepreneurial universities would come to view research data as assets to be hoarded and marketed, rather than as knowledge to be freely shared, he says.

The US science community fought this battle as recently as 1996, when it successfully lobbied to block a proposed treaty on database protection being considered by the World Intellectual Property Organization (see Nature 384, 299; 1996).

But the ease with which the Coble bill moved through the House - despite letters of opposition and testimony from science and library associations — suggests that the

\section{Telescopes track down lost spacecraft}

[MUNICH] Ground-based radiotelescopes have located the $\$ 1$ billion US-European solar space mission SOHO, which slipped out of radio contact at the end of June.

Until now, all attempts to find the spacecraft have failed. But signals transmitted last week by the US National Astronomy and Ionosphere Center in Arecibo, Puerto Rico - the location for the film Contact - were reflected back to Earth and picked up by the 70-metre dish of NASA's Deep Space Network in Goldstone, USA.

The batteries of SOHO (the Solar and Heliospheric Observatory) appear to have been drained during the craft's unsuccessful attempt to maintain its correct orientation towards the Sun, after this had been lost during maintenance (see Nature 394, 5;
1998). In its current orientation, edge-on to the Sun, the spacecraft cannot use solar energy to recharge the batteries.

But engineers at NASA and the European Space Agency have confirmed that SOHO is spinning slowly, at exactly the rate they had predicted, suggesting that little structural damage has occurred. They have also confirmed that SOHO has not yet shifted from its correct orbit.

Scientists are still hoping that SOHO will, in the course of its current orbit, move into a position where it leans sufficiently towards the Sun to allow recharging of its batteries. This might happen within three months. Once recharged, SOHO could once again respond to radiocommands and transmit data - providing no serious damage has been done. community's concerns are not taken seriously. "We were very ineffective at making our case, even with people [like Coble] who are our friends," says Stewart.

She and others argue that, although the proposed legislation appears to exempt researchers, news organizations and other non-profit users from restrictions on data use, the bill's language is so vague that it offers little protection for scientists. "A real exemption for universities could go a long way" towards easing the research community's fears, says Stewart.

Coble accuses scientists of worrying too much. But George Brown of California, the senior Democrat on the House Science Committee, answered that "[scientists] may be worried because they do not understand the bill," and called for Congress to go slower in passing the antipiracy legislation. "I would like to alert a broader audience to the fact that there could be some flaws."

The White House has been silent on the issue, but is expected to weigh in with its opinion this week, in the form ofletters to key senators. The Office of Science and Technology Policy has been formulating the administration's position, and President Bill Clinton's National Economic Council has discussed it.

The Coble bill's quick passage through the House was aided by the work of high-powered lobbyists, including Laura Tyson, once Clinton's chief economic adviser and now a consultant to Reed Elsevier and Thomson. The Grams bill is expected to move more slowly through the Senate, giving opponents hope that it can be modified or thrown out.

Political divisions over the issue are not clear cut. The Information Technology Association of America (ITAA), which opposes the legislation, counts among its members large database owners such as Dun \& Bradstreet, as well as companies such as Microsoft, Netscape, MCI and America Online.

The ITAA argues that concerns about piracy should be addressed with a more circumscribed amendment to existing copyright law. One critic of the Coble-Grams bill says it tries to "kill a small problem with an assault rifle".

Several groups, including the ITAA and the Institute of Electrical and Electronics Engineers (IEEE), have suggested amendments to the bill to make it less onerous to researchers. Instead of prohibiting the "use" and "extraction" of data, the IEEE suggests a ban on "unauthorized selling and distribution of data", for example.

The ITAA and its allies hope this kind of modification will turn the antipiracy law into something both sides can live with. "We obviously want greater database protection," says the association's general counsel, Marc Pearl. "We just don't think this [bill] is the best approach." 